\title{
Stretch reflexes of triceps surae in normal man
}

\author{
A BERARDELLI, M HALLETT, C KAUFMAN, E FINE, W BERENBERG, SR SIMON
}

From the Rehabilitation Engineering Center at Harvard-MIT, Section of Neurology, Department of Medicine, Brigham and Women's Hospital, the Departments of Orthopedic Surgery and Pediatrics, Children's Hospital Medical Center and the Departments of Neurology, Orthopedic Surgery and Pediatrics, Harvard Medical School

SUMMARY In order to learn more about stretch reflex behaviour of triceps surae, normal human subjects sat in a chair with one foot on a platform attached to a torque motor that produced phasic dorsiflexion displacements of the ankle. EMG activity was recorded from triceps surae and responses were obtained for various conditions. When the subject's foot was relaxed, stretch of triceps surae produced a single EMG component at short-latency which increased in magnitude with increasing velocity of stretch. The response was not altered if the subject was asked to plantarflex or dorsiflex the ankle voluntarily when he felt the perturbation. It was reduced by vibration of the Achilles tendon. If the triceps surae was stretched while the subject plantarflexed his ankle, the short-latency response was followed by one and sometimes two long-latency responses. Like the short-latency reflex when the foot was relaxed, none of these responses was altered by the subject's planned movement after feeling the perturbation. All of the responses were suppressed to a similar degree by vibration. The long-latency reflexes depended on longduration of stretching and relatively slow acceleration of stretch. The reflexes persisted after anaesthesia to the foot suggesting that muscle afferents were responsible. Interactions between $\mathrm{H}$-reflexes and stretch-reflexes revealed that the afferent volley producing a stretch reflex acted like the afferent volley producing a small $\mathrm{H}$-reflex. Responses at an interval of $30 \mathrm{~ms}$ to both an electrical stimulus for an $\mathrm{H}$-reflex and a stretch stimulus were possible if the electrical stimulus produced only a small $\mathrm{H}$-reflex and if the subject had been plantarflexing the ankle. The shortlatency reflex when the foot was relaxed or exerting a background force appears to be the monosynaptic, Ia mediated stretch reflex. The physiological properties of the long latency reflexes are similar to those of the short-latency reflex, and they may represent, at least to a certain extent, response of the motor neuron pool to successive Ia bursts.

Stretch of contracting muscle produces a series of responses. The first, at "short-latency", has usually been shown to be equivalent to the monosynaptic reflex. If the muscle is active at the time of the stretch then there will be one or more "longlatency" responses following the early response, first seen by Hammond, ${ }^{1}$ which also appear to be reflex in nature. Following these responses are additional events which can be strongly influenced by voluntary intent. The precise role of the short and long-latency responses in control of movement is unclear; speculations include the idea of a mechanism to control

Address for reprint requests: Mark Hallett, MD, Section of Neurology, Brigham and Women's Hospital, 75 Francis Street, Boston, MA 02115, USA.

Received 18 October 1981

Accepted 18 November 1981 muscle length ${ }^{2}$ or a mechanism to control muscle stiffness. ${ }^{3}$

While long-latency reflexes have been described in various muscle groups in the upper extremity including the long flexor of the thumb, ${ }^{2}$ wrist flexor and extensor ${ }^{45}$ and biceps, ${ }^{67}$ previous investigations of the triceps surae have failed to reveal similar responses. ${ }^{8-10}$ Independent of whether the muscle is active or not a short latency reflex at $40-50 \mathrm{~ms}$ after the stretch is prominent in triceps surae and presumably reflects the monosynaptic spinal reflex. Its mechanism has been studied in detail by Gottlieb and Agarwal, ${ }^{8}$ and by Kearney. ${ }^{10} \mathrm{~A}$ small second response following the short latency reflex has been described by Gottlieb and Agarwal in normal subjects and the properties of this response are similar, but not identical, to the short-latency reflex.

Another response in the triceps surae, called the 
functional stretch reflex by Melvill Jones and Watt ${ }^{11}$ and the post-myotatic response by Gottlieb and Agarwal $^{9}$ comes at a latency of $120 \mathrm{~ms}$. The functional stretch reflex depends in large part on intent and thus seems to be voluntary, but there are some differences from ordinary voluntary responses which will be discussed later. Nashner ${ }^{12}$ has identified a stretch response at about $100 \mathrm{~ms}$ latency in ankle muscles of standing man that he calls the functional stretch reflex but proof of its analogy to the functional stretch reflex of Melvill Jones and Watt, or to long-latency reflexes seen in other muscles, is lacking.

Quantitative analysis of the effect of different mechanical parameters of the stretch on the magnitude of components of the long-latency responses in the long thumb flexor has suggested that long, slow stretches produce larger responses. ${ }^{13}$ For this reason we began to study responses to stretch of the triceps surae at velocities which are slower than those previously studied in order to attempt to identify long-latency responses more analogous to those seen in upper extremity muscles. It is relevant to observe in this regard that in walking the maximal rate of rotation of the ankle is $200 \%$ s and these rates are lower than those studied previously. It has turned out that long-latency reflex components do appear with these slower stretches.

\section{Materials and methods}

Twenty normal subjects (aged from 20 to 40 years) sat in a chair with one foot, usually the left, strapped to a platform with the hip and knee at 90 degrees. The base of the chair was connected to a large metallic frame into which was incorporated a torque motor (Magnetic Technology P/N H5500-750-040). Connected to the shaft of the motor was the platform for the foot. A system of platform supports was adjustable to enable alignment of the ankle's "axis of rotation" with the platform's axis of rotation. An infinite resolution plastic film potentiometer (Bourns Model 6674, Custom Precision) attached to the shaft was used as an angular position transducer. An angular velocity transducer which was a permanent magnet DC Tachometer (Servo Tek SA 72474-2 Size 11) also was attached to the shaft. The torque produced between the motor and the platform was measured by a custom designed strain gauge and this information could be made available to the subject by deflection of a meter needle.

The platform attached to the torque motor was controlled by computer and made quick dorsiflexion movements at specified peak velocities $(100-250 \%$ s). The peak velocities were attained at $50-100 \mathrm{~ms}$ into the course of the movement. The starting angle and termination angle could be independently specified. The computer produced a position command signal which was summed with the angular position and angular velocity in an analogue network to generate a position error-signal. The error signal was supplied to a 525 Watt linear power amplifier (Torque Sys- tems, Inc Modal PA-601) which drove the torque motor. This feed-back mechanism resulted in relatively smooth operation of the pedal and limited the maximal velocity of pedal to $200-250 \%$ s. Electrical activity from the lateral gastrocnemious and the tibialis anterior muscles was recorded with Jacobson surface electrodes PDL-3 (Project and Design Laboratory, University of Utah) (gain of about 310 and a bandwidth of $5 \mathrm{~Hz}$ to $17000 \mathrm{~Hz}$ ) which contained an at-the-site differential preamplifier. The small size of preamplifier allowed it to be placed on the skin above the muscle being monitored. The ground electrode was a Beckman silver-silver chloride, usually placed on the knee. The EMG signals were full wave rectified and then filtered by a second order low-pass Butterworth filter which reduced the signal by $3 \mathrm{db}$ at $90 \mathrm{~Hz}$. The EMG signals, the angular positions of the foot and the torque on the platform were sampled by the computer at $2 \mathrm{~ms}$ intervals.

For the quantitative analysis of the EMG responses we have described the stretches in terms of peak acceleration rather than velocity, because commands for greater velocity produced an earlier peak of the velocity as well as an increase in velocity, so that acceleration was a better descriptor of the mechanical perturbation. In addition, the platform began to move slowly so that it was often difficult to specify the precise onset of the perturbation; for this reason the latency of the EMG responses was measured from the electronic command to move the platform to the onset of the EMG response. This clearly overestimates the true biological latency. The duration of each EMG component was measured by visual inspection. The amount of EMG activity in a component was calculated by integrating the rectified and filtered EMG record using the computer. At the beginning of the experiment the subject was asked to press against the pedal with maximal strength. The extent of needle displacement on the torque meter and the amount of EMG activity was noted. This "maximal EMG activity" was also integrated using the computer. The integrated EMG activity in a component of a stretch response could then be measured as a percentage of the maximal EMG activity. This value was calculated by dividing the ratio of integrated value of the response to the duration of the response by the ratio of the integrated value of the maximal EMG activity to its duration and multiplying times 100 . At other times we calculated the magnitude of a response by dividing the integrated EMG of the response by the ratio of the integrated value of the maximal EMG activity divided by its duration (without taking into consideration the duration of the EMG response). The first method produced a number related to an average increase in EMG activity over the time of the response while the second method produces a number related to the absolute amount of EMG activity in the response without regard for its duration. There were no major differences in results of any experiment with these two techniques and all of the results in the paper utilise the first method.

Each specified velocity of stretch was repeated 10 times in a random sequence and the results were separately averaged. Four experimental paradigms were used for this study.

Experimental paradigm I. No background force

(A) Stretch reflexes The subject sat with his foot relaxed 
on the platform and he was told to do nothing. The initial angle was $-10^{\circ}$ and at random times the ankle was dorsiflexed to $+5^{\circ}$ at five different specified velocities $(100$, $125,150,175,250$ degrees/s). Each velocity was repeated ten times in a random sequence and the results of each were separately averaged. This experiment was performed in 20 subjects.

(B) Voluntary influences The subject sat with his foot relaxed on the platform, but this time he was given at random one of two tasks to perform when he perceived the perturbation: (1) push (plantarflexion of the ankle), or (2) assist (dorsiflexion of the ankle). All perturbations were from $-10^{\circ}$ to $+5^{\circ}$ and the specified velocity was 200 degrees/s. Each task was performed 10 times and the results averaged. This experiment was performed in five subjects.

(C) Vibration In six subjects, vibration was applied manually to the tibialis anterior or Achilles tendon using a physical therapy vibrator (Foredom Electric Company Series 97). Various degrees of pressure were exerted and the frequency was varied between $50-150 \mathrm{~Hz}$.

\section{Experimental paradigm II. Background force}

(A) Stretch reflexes This experiment was similar to A of the paradigm I except that the subject exerted a plantarflexing torque onto the platform of $20 \%$ of maximal force while waiting for the perturbation. The $20 \%$ force was determined using the torque monitor and comparison to maximal effort. Again, 10 repetitions of five different velocities $(100,125,150,175,250$ degrees/s) were given in a random order and the results for each averaged. This experiment was performed in 20 subjects.

(B) Voluntary inftuences This experiment was similar to $B$ of the paradigm I, except that the subject exerted plantarflexing torque into the platform of $20 \%$ of maximal force. He was given one of two tasks, to push or assist after receiving a standard perturbation from $-10^{\circ}$ to $5^{\circ}$ at 200 degrees/s. This experiment was performed in five subjects. (C) Vibration In six subjects vibration was applied on Achilles tendon or tibialis anterior.

(D) Ischaemia The effect of ischaemia on long-latency stretch reflexes was studied in two subjects. Ischaemia of the foot was produced by application of cuff around the ankle inflated at $200 \mathrm{~mm} \mathrm{Hg}$. Testing was carried out when cutaneous sensitivity below the cuff was absent and ability to detect movement of the ankle was reduced to movements of greater than $5^{\circ}$. It was suspected that ability to detect large ankle movements was due at least in part to obligatory movement of the cuff with ankle movement. The stretch reflex was recorded with background force at 200 degrees/s of velocity from $-10^{\circ}$ to $5^{\circ}$.

\section{Experimental paradigm III}

Stretch reflexes with different duration of stretch were studied. Changes of duration were determined by varying the excursion of the pedal. These experiments were conducted with and without background force. Four subjects were tested for three different sets of experiments. (1) $15^{\circ}$, $10^{\circ}$, and $5^{\circ}$ of pedal displacements were used. The specified velocity was 200 degrees/s and the starting point was $-10^{\circ}$. (2) $9^{\circ}, 6^{\circ}$, and $3^{\circ}$ of pedal displacements were used. The specified velocity was 200 degrees/s and the starting point was $-10^{\circ}$. (3) Stretches with $5^{\circ}$ of displacement and 250 degrees/s velocity (starting point $0^{\circ}$ ) were compared with stretches with $15^{\circ}$ of displacement and 100 degree/s velocity (starting point $-10^{\circ}$ ).

\section{Experimental paradigm $I V$}

Interaction between the H-reflex and stretch reflex of triceps surae were studied in three subjects. The stretch reflex was obtained at 200 degrees/s from -10 to +5 degree of pedal displacement. The H-reflex was obtained with electrical stimulation of the posterior tibial nerve in the popliteal fossa using a bipolar surface electrode. Stimulus duration was $1.0 \mathrm{~ms}$ and amplitude was adjusted to produce either a minimal or maximal $\mathrm{H}$-reflex. A minimal $\mathrm{H}$-reflex was defined as the $\mathrm{H}$-reflex seen just above threshold and recognisable by eye on each trial. A maximal $\mathrm{H}$-reflex was defined as the $\mathrm{H}$-reflex of highest amplitude. Three different sets of experiments were performed. (1) Stimulation for the $\mathrm{H}$-reflex was delivered before the stretch at intervals from $0-1500 \mathrm{~ms}$. This was performed with and without the subject generating background force. The effects of different magnitudes of H-reflex on the stretch reflex were evaluated. (2) Stimulation for the $\mathrm{H}$-reflex was delivered after the stretch produced by the torque motor at intervals from 50-500 ms. Experiments were conducted with different magnitude of $\mathrm{H}$-reflex and with and without background force. (3) Interaction between two H-reflexes of similar magnitude was studied at various intervals, with and without background force.

\section{Results}

PARADIGM I: NO BACKGROUND FORCE

(A) Stretch reflexes A single EMG component was recorded from lateral gastrocnemious after a sudden dorsiflexion of the foot (fig 1). The latency varied from 50-80 ms in different subjects and was shorter and more stable at fast accelerations. The interval between the peak acceleration and the beginning of the response varied from about $20-30 \mathrm{~ms}$. The duration varied from $17-40$ ms but was relatively stable with different accelerations in the same subject. The magnitude of this response increased with increasing acceleration of the stretch (fig 2). We will call this response the short-latency reflex noting its similarity to the myotatic reflex as previously studied by Agarwal and Gottlieb. ${ }^{8}$

(B) Voluntary infuences The latency, duration and magnitude of the short-latency reflex were not modified if the subject made a dorsiflexion or a plantarflexion movement when he perceived the perturbation. When the subject performed a plantarflexion of the foot a large EMG component was present at about a latency of $150-160 \mathrm{~ms}$. This component was considerably reduced or absent when the subjects made a dorsiflexion movement. In the assist task a large EMG response at $150 \mathrm{~ms}$ latency was recorded from tibialis anterior. 


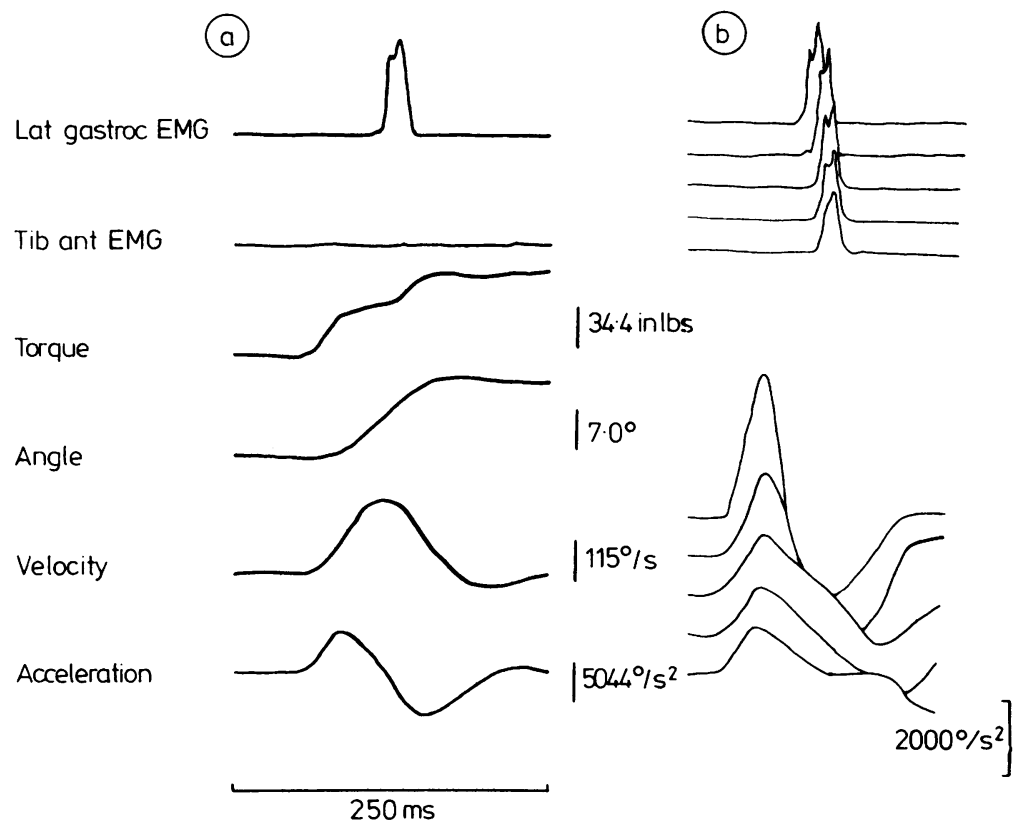

Fig 1 (A) Short latency reflex of lateral gastrocnemius muscle to a dorsiflexion stretch when the subject was at rest. This response is the average of 10 single stretches. No EMG response is seen in the tibialis anterior (tib ant).

(B) Behaviour of the short-latency reflex (upper part) with decreasing accelerations of stretch (lower part) when the subject was at rest. Each trace is an average of 10 trials.

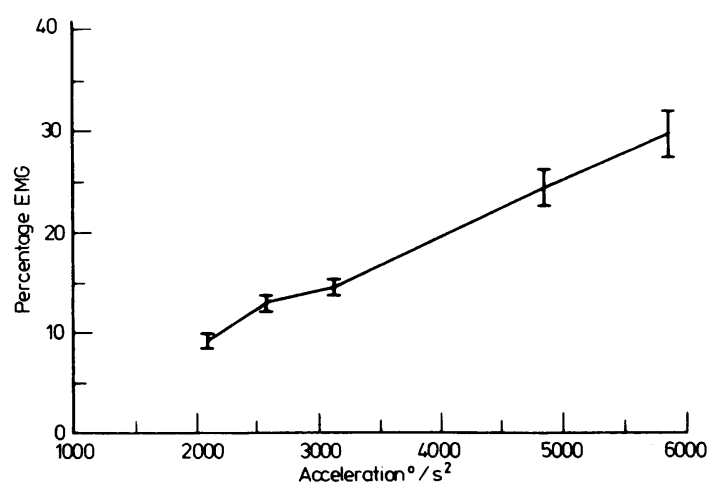

Fig 2 The magnitude (mean $\pm 1 S E ; n=10$ ) of the short-latency reflex when normal subjects were at rest plotted against the acceleration of the stretch. The short-latency reflex has been calculated as percentage of the maximal EMG activity.

(C) Vibration The short latency reflex was reduced by a vibration of the Achilles tendon or of the tibialis anterior in all the subjects tested. The degree of inhibition of the reflex depended on the pressure of the vibrator on the limb.
PARADIGM II: BACKGROUND FORCE

(A) Stretch reflex Each subject exerted a plantarflexion torque onto the platform of $20 \%$ of his maximal force while waiting the perturbation. In this circumstance the EMG response-was longer in duration than without background force. Often two or three discrete EMG components could be identified (fig 3). The first component was similar in duration to the short-latency reflex recorded without background force. Its latency was slightly faster (42-68 $\mathrm{ms}$ ), and became less with faster stretches.

The other two responses can be considered longlatency stretch reflexes. The first of the two had a latency of 70-105 ms and was present in all the subjects tested. The second of the long-latency responses had a latency of $93-130 \mathrm{~ms}$ and was present only in $30-40 \%$ of the subjects. The latency of both components became less with faster stretches.

A quantitative analysis of the magnitude of the short latency reflex and the two long latency reflexes in 10 different subjects is shown in fig 4 . The magnitude of the short latency reflex was greater than that of the two long-latency reflexes, and than the short-latency reflex without background force. The first long latency reflex increased in magnitude 


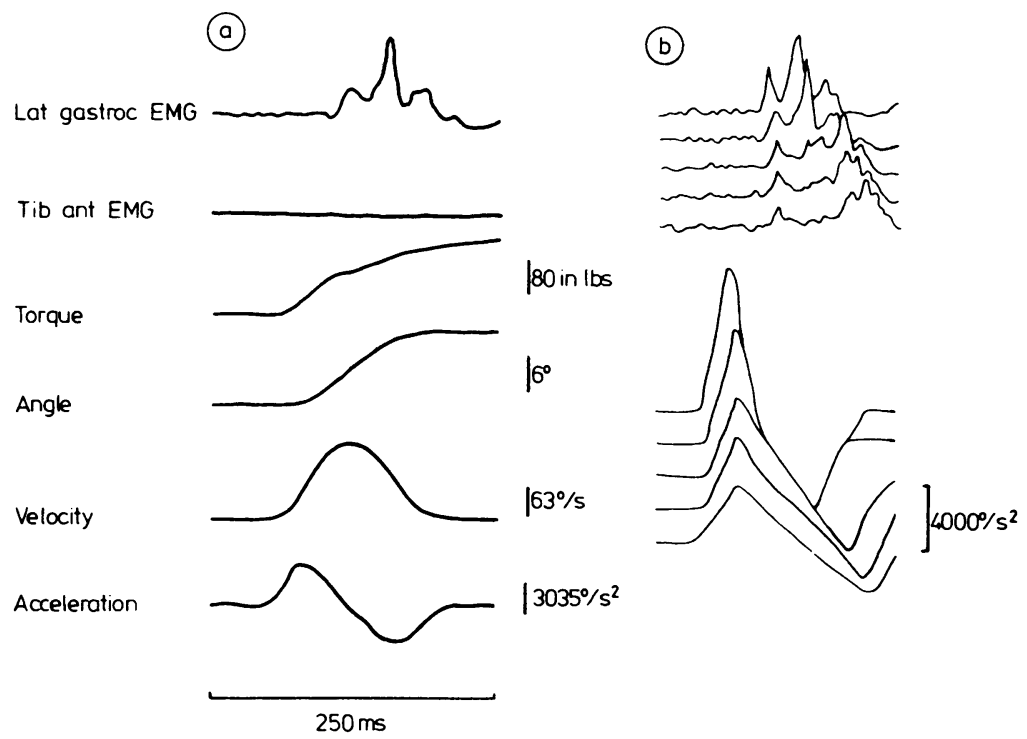

Fig 3 (A) Responses in lateral gastrocnemius to a dorsiflexion movement while the subject was exerting $20 \%$ force on the platform. A short latency reflex is followed by two long-latency EMG components. No response is seen in tibialis anterior. Each trace is an average of 10 trials. (B) Behaviour of the short and long-latency reflexes (upper part) at decreasing accelerations of stretch (lower part). Each trace is the average of 10 trials.
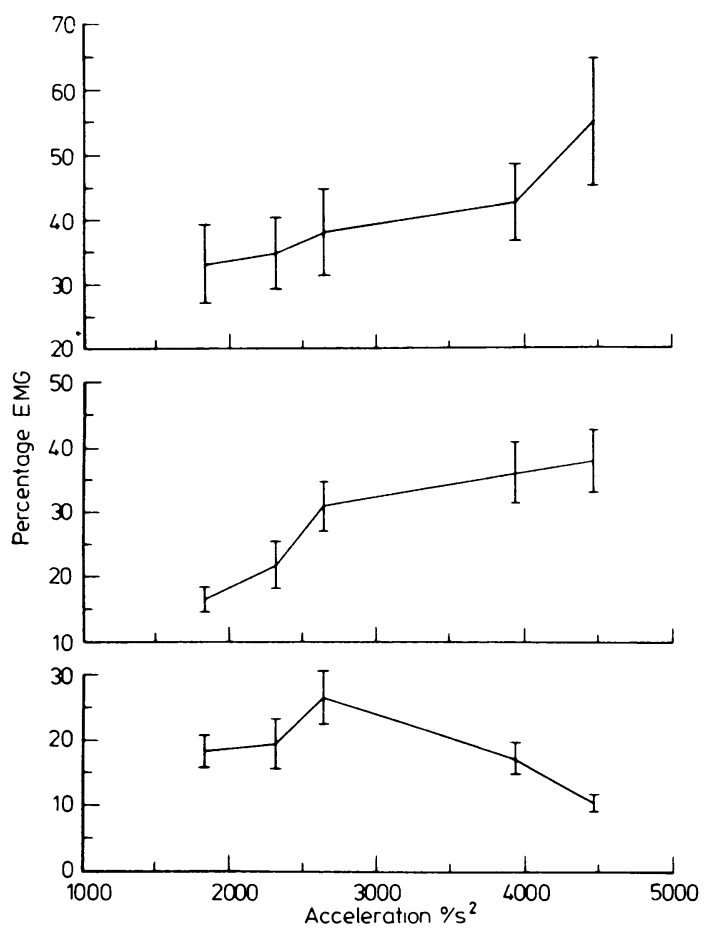

Fig 4 Behaviour of the short and long-latency reflexes when the subject was exerting background force with increased acceleration of stretch. The percentage of maximal force of each component (Mean $\pm 1 S E ; n=10)$ is plotted against the acceleration of the stretch. The top graph shows the behaviour of the short-latency reflex, the middle graph shows the behaviour of the first long-latency reflex, and the bottom graph shows the behaviour of the second long-latency reflex. 


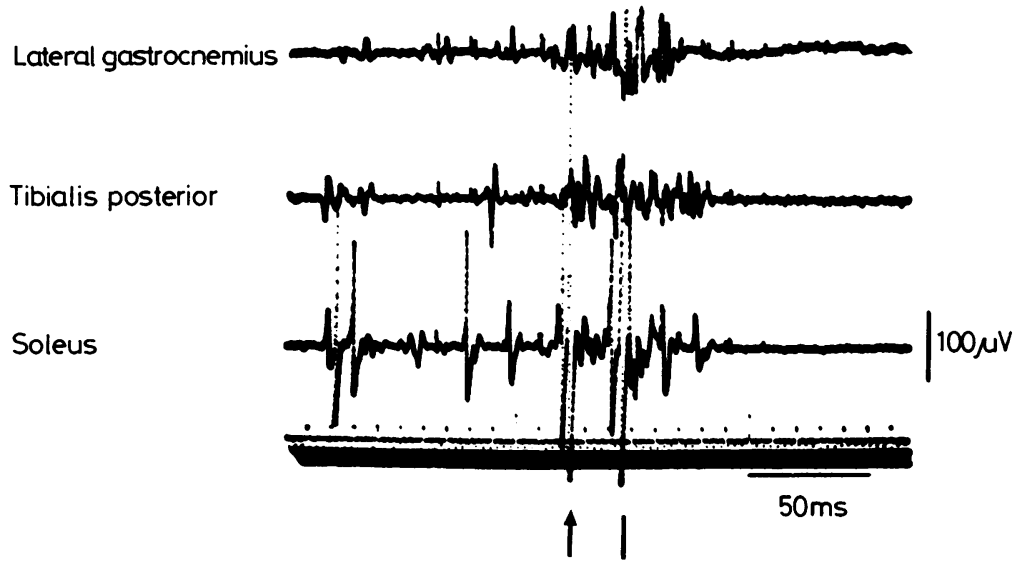

Fig 5 EMG activity recorded with concentric needle electrodes from lateral gastrocnemius, tibialis posterior and soleus muscles. This is a single trial with dorsiflexion movement beginning at $50 \mathrm{~ms}$ after the onset of the sweep. Different bursts of EMG activity are present in all muscles at the same latency. The arrow indicates the short-latency reflex and the bar indicates the onset of the long-latency reflex which seems to have two components in this trial.
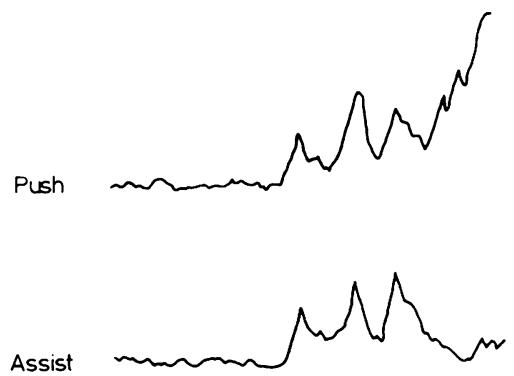

$250 \mathrm{~ms}$

Fig 6 Behaviour of long-latency reflexes during voluntary task. In "push" the subject exerted a plantar-flexion when he perceived the perturbation, and in "assist" a dorsi-flexion. In the push task a large EMG component is present after the long-latency reflexes. Each trace is the average of 10 single trials. The command to move the pedal came at $50 \mathrm{~ms}$ after the beginning of the sweep.

with increasing acceleration of stretch showing a less pronounced increase at faster acceleration and sometimes tended to plateau. The duration varied from 15-42 ms. The second long-latency reflex had a greater probability of occurrence and a longer latency at slow velocity of stretch and tended to disappear or reduce in magnitude and latency at faster acceleration. The change in latency was most dramatic for this component. The duration of the second long-latency reflex varied from $20-50 \mathrm{~ms}$.

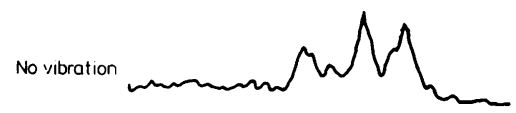

Vibration

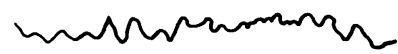

$250 \mathrm{~ms}$

Fig 7 Behaviour of the short and long-latency reflexes without (upper part) and with vibration (lower part). This is the average of 10 single trials. The command to move the pedal came at $50 \mathrm{~ms}$ after the beginning of the sweep.

Long-latency stretch reflexes also have been observed when the position of the hip and the knee was varied from $90^{\circ}-120^{\circ}$, but were absent when the subjects exerted a dorsiflexion torque instead of a plantarflexion. The dorsiflexion torque also produced an inhibition of the short-latency reflex.

Long-latency reflexes were always present when the average of 10 single stretches was performed, but did not appear to be present on each single stretch. In two subjects concentric needle electrodes 
A
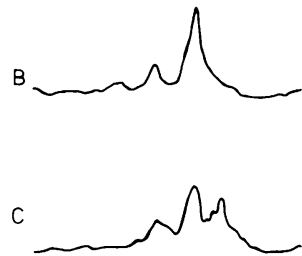

C
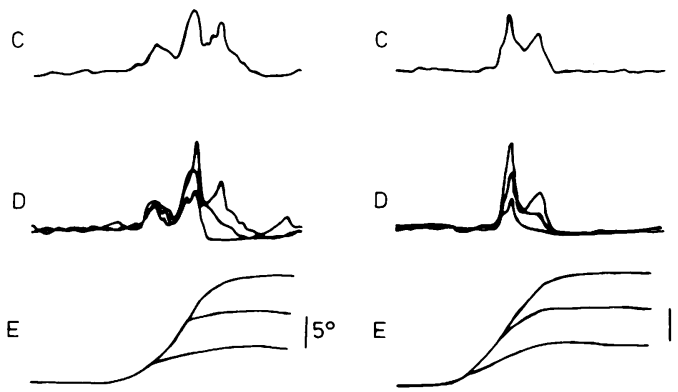

E

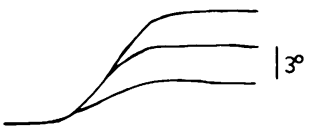

$250 \mathrm{~ms}$

Fig 8 Stretch reflex of lateral gastrocnemius with different duration of stretch. Left side: (A) EMG response with $5^{\circ}$ of pedal displacement $(B) E M G$ response with $10^{\circ}$ of displacement (C) EMG response with $15^{\circ}$ of displacement. $(D)$ is a superimposition of $A, B$ and $C$. (E) shows the angular position of the foot in each of the three circumstances. Right side: $(A)$ EMG response with $3^{\circ}$ of pedal displacement. (B) EMG response with $6^{\circ}$ of displacement. (C) EMG response with $9^{\circ}$ of displacement. (D) is a superimposition of $A, B$, and $C$. (E) shows the angular position of the foot in each of the three circumstances. Each trace is the average of 10 single trials. were used to record EMG activity from soleus, tibialis posterior, lateral and medial gastrocnemious. Short and long-latency reflexes appeared in all 11 muscles with the same latency (fig 5).

(B) Voluntary influences In this experiment the subjects were instructed to plantarflex or dorsiflex the ankle when they perceived the dorsiflexion perturbation. The short and long-latency reflexes did not vary during these tasks (fig 6). In the push task a large EMG component came immediately after the long-latency responses at a latency of about 150 $160 \mathrm{~ms}$. In the assist task the late EMG activity was considerably reduced or absent, but a large EMG component was recorded at $150 \mathrm{~ms}$ from the tibialis anterior.

(C) Vibration In six subjects the Achilles tendon or tibialis anterior was vibrated at various levels of manual pressure and at various frequencies attempting to get differential effects on the short-latency reflex and the long-latency reflexes. The degree of inhibition was not selective for the different EMG components but was similar for each component in every condition (fig 7).

(D) Ischaemia Long-latency reflexes were studied before and after application of a cuff around the ankle producing anaesthesia of the foot. The long-latency reflexes did not show any variation in magnitude, latency or duration.

\section{EXPERIMENTAL PARADIGM III}

This experiment was undertaken in order to identify the effect of different duration of stretch on longlatency EMG responses.

In the first set of these experiments, we compared the standard $15^{\circ}$ movement to movements of $10^{\circ}$ and $5^{\circ}$ (left side of fig 8 ). These stretches had similar
A
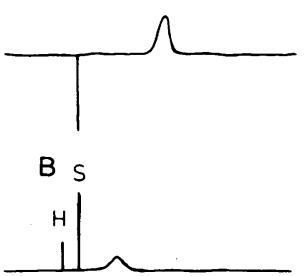

C

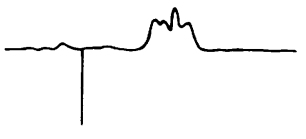

D S

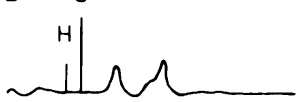

E

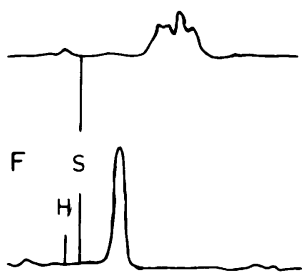

$250 \mathrm{~ms}$

Fig. 9 Interaction of $H$-reflex with a subsequent stretch reflex. (A) stretch reflex without background force. $(B)$ small $H$ reflex delivered $30 \mathrm{~ms}$ before the stretch. The small $H$ is present, the stretch reflex is absent. $(C)$ stretch reflex with background force. (D) small $H$ reflex delivered before the stretch with background force. $H$ reflex and stretch reflex are both present. (E) stretch reflex with background force (same as $C)$. (F) maximum $H$ reflex delivered before the stretch with background force. The $H$ reflex is present, the stretch reflex is absent. Each trace is the average of 10 trials. 


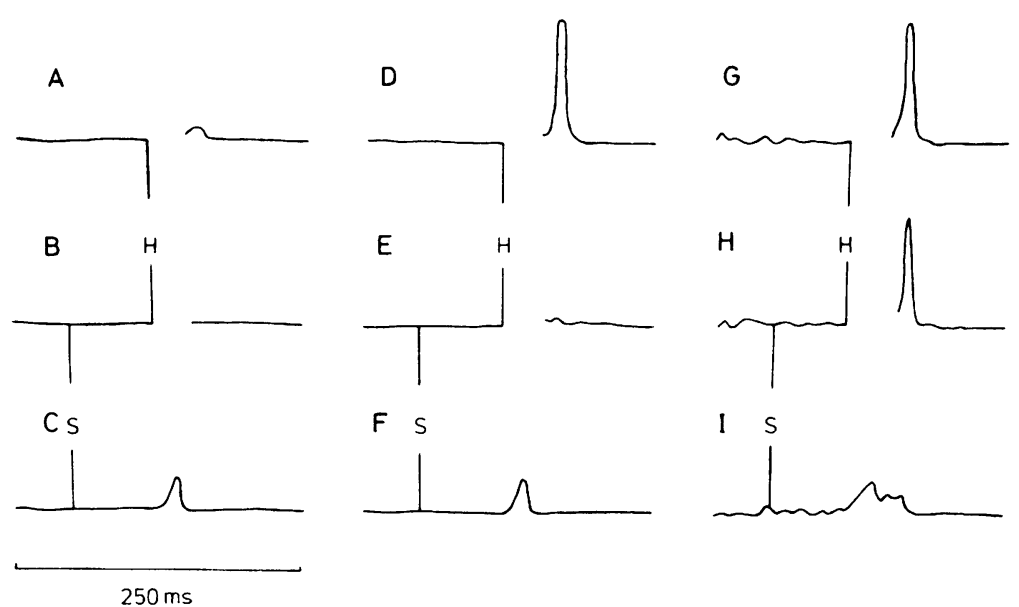

Fig 10 Interaction of stretch reflex with a subsequent $H$ reflex. The stimulus for the $H$ reflex produced a large artefact in these records and the time of the artefact is blanked in the illustrations. A-F all without background force. (A) small $H$ reflex. (B) stretch reflex delivered before a small $H$ reflex. The $H$ reflex is absent, the stretch reflex is covered by the stimulus artefact. (C) stretch reflex. (D) maximum $H$ reflex. $(E)$ stretch reflex before a maximum $(H$.$) The H$ reflex is absent, the stretch is covered by the stimulus artefact. (F) stretch reflex (same as $C)$. (G) $(H)$, and $(I)$ all with background force. (G.) maximum $H$ reflex. $(H)$ stretch reflex before the $H$ reflex. The $H$ reflex is still present. The stretch reflex is covered by the stimulus artefact. (I) stretch reflex. Each trace is the average of 10 trials.

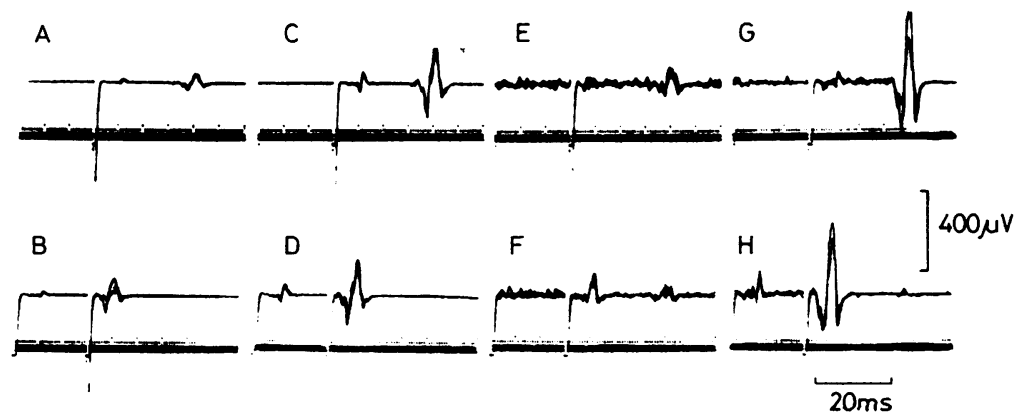

Fig 11 Interaction of the $H$ reflex at 30 ms intervals. $A, B, C$ and $D$ all without background force. $(A)$ small $H$ reflex. $(B)$ stimuli for two small $H$ reflexes are delivered, but the second $H$ reflex is absent. $(C)$ maximum $H$ reflex. $(D)$ stimuli for two maximum $H$ reflexes are delivered, but the second one is absent. $E, F, G, H$ all with background force. $(E)$ small $H$ reflex. $(F)$ stimuli for two small $H$ reflexes are delivered and the second $H$-reflex is decreased, but present. $(G)$ maximum $H$ reflex. $(H)$ stimuli for two maximum $H$ reflexes are delivered but only the first $H$ reflex is present. The time of stimulus for the $H$ reflex can be noted on the illustration as $a$ brief downward artefact. Each record is a superimposition of three individual trials.

accelerations but the durations were shorter for the shorter stretches. The approximate durations of stretch were $110 \mathrm{~ms}, 90 \mathrm{~ms}$ and $70 \mathrm{~ms}$. The second long latency reflex was present only with the longest duration stretch. The second set of experiments compared stretches of $3^{\circ}, 6^{\circ}$ and $9^{\circ}$ which occupied about $50 \mathrm{~ms}, 60 \mathrm{~ms}$ and $80 \mathrm{~ms}$ respectively (right side of fig 8). The first long-latency reflex was very small with the stretch of intermediate duration and became prominent only with the largest stretch.

In another set of experiments, long-latency stretch reflexes were present in all the subjects with 
long-duration $(110 \mathrm{~ms})$ and slow velocity of stretches ( 100 degree/s), but were absent with short duration $(50 \mathrm{~ms})$ and fast velocity (250 degrees/s) stretches.

\section{EXPERIMENTAL PARADIGM IV}

(1) A maximal H-reflex produced before an expected stretch reflex inhibited the stretch reflex when the interval between the stimuli for the $\mathrm{H}$-reflex and the stretch reflex was less than $170 \mathrm{~ms}$. (Since the latency of the $\mathrm{H}$-reflex is approximately $30 \mathrm{~ms}$ and the latency of the stretch reflex approximately $60 \mathrm{~ms}$ the latency difference between the expected responses is $30 \mathrm{~ms}$ more than the interval between the stimuli.) The degree of inhibition increased as the interval decreased and became complete when the interval was less than $50 \mathrm{~ms}$. This was true both at rest and with background force. A minimal H-reflex produced by stimulation at the time of stretch (interstimulus interval of $0 \mathrm{~ms}$ ) inhibited the stretch reflex when the ankle was at rest but had little effect on the stretch reflex when the subject was exerting background force. Hence for short interstimulus intervals the only way to get a stretch response was for the $\mathrm{H}$-reflex to be minimal and for the subject to be exerting background force (fig 9).

(2) At rest, a stretch reflex produced before an expected $\mathrm{H}$-reflex inhibited the $\mathrm{H}$-reflex when the interval between the stimuli was less than $230 \mathrm{~ms}$. (The latency difference between the responses was $30 \mathrm{~ms}$ less than the interval between the stimuli.) The degree of inhibition increased as the interval decreased and became complete even for a maximal $\mathrm{H}$-reflex, when the interval was less than $110 \mathrm{~ms}$. When the subject was exerting background force, however, a stretch response produced by a stretch $60 \mathrm{~ms}$ prior to the stimulation for the $\mathrm{H}$-reflex did not inhibit even a minimal $\mathrm{H}$-response. Hence for short intervals a stretch response inhibited a maximal $\mathrm{H}$-reflex at rest, but not even a minimal $\mathrm{H}$-reflex with background force (fig 10).

(3) A maximal H-reflex inhibited a second H-reflex when the interval between the stimuli was less than $200 \mathrm{~ms}$. This was true when the ankle was at rest or if background force was exerted. For the situation at rest, the degree of inhibition increased as the interval decreased and became complete when the interval was less than $80 \mathrm{~ms}$. A minimal $\mathrm{H}$-reflex also inhibited a second minimal $\mathrm{H}$-reflex at a $30 \mathrm{~ms}$ interval when the ankle was at rest. When background force was exerted, however, a minimal $\mathrm{H}$-reflex did not inhibit a second minimal $\mathrm{H}$-reflex at $30 \mathrm{~ms}$ interval. Hence, for short interstimulus intervals, it was possible to get two successive $\mathrm{H}$-reflexes only if there was background force exerted and if the $\mathrm{H}$-reflex was small (fig 11).

\section{Discussion}

\section{STRETCH REFLEX WITHOUT BACKGROUND} FORCE

When the triceps surae were stretched while the subject's foot was relaxed on the pedal a single EMG response was recorded, followed by a pause and subsequently by another response highly modifiable by intent. The early response we have called the short-latency reflex. We refer to it as a "reflex" since it is determined primarily on the basis of the mechanical parameters of the stretch and the biological state at the time of the stretch and is influenced only little by voluntary intent to modify it. This short-latency response also has been seen by previous investigators and the properties are similar. ${ }^{810}$ Some investigators have found that voluntary intent to modify this response was possible, where we have found lack of modifiability, but even in their hands the difference with intent was small. ${ }^{3614}$ The later response, modifiable by intent, we consider voluntary simply because it is modifiable. This division of reflex and voluntary is simplistic, overlooking possible complex learned reactions, ${ }^{315}$ but it is a useful division of different types of phenomena and has been utilised by many previous investigators. 245713

The short-latency reflex has a latency comparable to the ankle jerk, it increases in magnitude with increased acceleration of stretch and is completely suppressed by vibration. These features are consistent with the monosynaptic reflex mediated by group Ia afferents, similar to the ankle jerk itself. The latency is longer than the ankle jerk, but the stretch stimulus is much slower in onset than is a tendon tap. Some of this slowness is purely mechanical coming from the delay of the torque motor after the controlling input, but some could also be biological since the rate of muscle stretching is much slower. The notion that the short-latency reflex is Ia mediated is supported by the similarity of behaviour of this response and the $\mathrm{H}$-reflex. The $\mathrm{H}$-reflex has been demonstrated to result from monosynaptic activation of alpha motorneurons via Ia afferents similar to the tendon jerk. ${ }^{16}$ The $\mathrm{H}$-reflex is not identical to the tendon jerk (for example, the duration of the Ia afferent discharge is different), ${ }^{17}$ but the extent to which the H-reflex and the shortlatency reflex are similar is likely to be due to the dominant Ia afferent effects. The short-latency reflex can be suppressed by a prior $\mathrm{H}$-reflex and the $\mathrm{H}$-reflex can be suppressed by a prior $\mathrm{H}$-reflex. The same excitability curve, similar to that demonstrated by many previous investigators for two $\mathrm{H}$ - 
reflexes, ${ }^{18-20}$ has been demonstrated for all these circumstances. The conclusion that the short-latency reflex is a Ia mediated monosynaptic reflex is shared by previous investigators. ${ }^{810}$

\section{STRETCH-REFLEXES DURING BACKGROUND FORCE}

Several successive EMG responses were recorded if triceps surae was stretched while the subject applied a plantarflexing torque on the pedal. The first response, the short-latency reflex, had the same duration and latency of the short-latency response obtained without background force. It increased in magnitude with increased acceleration of stretch and it was totally suppressed by vibration. Presumably it was the same response as that seen without background force.

Following this short-latency response, an initial long-latency response was present in every subject and a second long-latency response was present in $40 \%$ of subjects. These long-latency responses preceded another response which was modifiable by intent and which we consider voluntary. This voluntary response was similar to that seen without background force. The long-latency responses which appeared before this voluntary response were not modified by prior instructions and, therefore, can be considered reflex or automatic components similar to the short-latency responses.

The behaviour of these long latency responses with changes in acceleration of the stretch was different from that of the short-latency reflex. In fact while the short-latency reflex increased in magnitude in a roughly linear fashion, the first longlatency response showed less pronounced increase at faster acceleration while the second one tended to disappear. These components have not been clearly demonstrated before. Gottlieb and Agarwal ${ }^{8} 9$ found a small response following their short-latency response which never was comparable in magnitude with these long-latency responses. In addition, the behaviour was different in that their second response continued to increase with increasing velocity. These long-latency reflexes depended on voluntary background force being present when the stretch was applied. This suggests that the increase in excitability of the motor neuron pool due to central drive is responsible for their appearance.

The long-latency response called the functional stretch reflex by Melvill Jones and Watt, ${ }^{11}$ and the post-myotatic response by Gottlieb and Agarwal ${ }^{9}$ seems to be analogous to the response which we have called voluntary. The physiology of this response has been studied in detail; it depends on the instruction to the subject and the magnitude of perturbating torque and may best be called a "triggered reaction". .21

PHYSIOLOGY OF THE LONG-LATENCY REFLEXES Experiments were undertaken to try to identify the mechanisms of these late responses and whether or not they were analogous to the long-latency reflexes seen by other investigators. The observation ${ }^{22}$ that motor neurons of muscles that work closely together receive Ia projections from each other raised the question of whether or not these responses could come from different muscular groups of triceps surae. Needle recording, however, showed that each muscular group produced short and long-latency responses simultaneously with the others. Another hypothesis is that the long-latency responses are mediated by cutaneous receptors on the sole of the foot or by joint receptors in the ankle. Experiments with anaesthesia at the level of the ankle showed that the long-latency responses were unchanged when the input from cutaneous and joint receptors was eliminated. The conclusion is that receptors in the muscle itself are mainly involved for these responses. Marsden et $a l^{23}$ reached the same conclusion for the long-latency responses in long-flexor of the big toe.

Long-latency responses could be mediated by group II fibres. We know that they have slower velocity of conduction than group Ia fibres and that there is some evidence that they contribute to the stretch reflex at least in the decerebrate cat. ${ }^{24-26}$ With the spike averaging technique it has been shown that group II afferents exert excitatory effect on alpha motoneurons of extensor muscles. ${ }^{27-32}$ It could be argued that group II afferents do not contribute to the long-latency reflexes since these reflexes are abolished by vibration and vibration affects mainly Ia afferents. On the other hand, vibration in man, as opposed to the decerebrate cat, clearly has some effect on group II fibres. ${ }^{163334}$ Thus the group II hypothesis cannot be excluded.

There is a growing body of evidence suggesting that a "long-loop" circuit through cerebral sensorimotor cortex contributes to those long-latency reflexes which have been described previously in upper extremity muscles. ${ }^{45-38}$ According to Pagni et al $^{39}$ the motor conduction time from internal capsule to flexor hallucis longus varies from $26-33 \mathrm{~ms}$ (and this is presumably similar to the time required to reach to triceps surae). We have recorded cerebral evoked potentials to a rapid phasic stretch similar to Starr et al. ${ }^{40}$ The latency of the first cortical wave following our stretch was $50 \mathrm{~ms}$. The estimated trans-cortical loop time should then be approximately $80 \mathrm{~ms}$. Either of the long-latency 
components, or both, could therefore result from activity in a trans-cortical loop.

One of the differences between short-latency reflexes and presumed long-loop reflexes in upper extremity muscles has been the different behaviour to vibration. Hendrie and $\mathrm{Lee}^{41}$ showed that in the wrist the spinal response (M1) can be inhibited by vibration while the long-latency responses (M2, M3) are unaffected. Similar results are seen in the human long thumb flexor (unpublished result by Bielawski in our laboratory) and in monkeys. ${ }^{42}$ The attempt to separate the early response from the late responses by vibration was unsuccessful in the triceps surae. In addition Marsden et $\mathrm{l}^{\mathbf{4 3}}$ showed that it is possible to remove selectively the spinal component of the stretch reflex of long-flexor of the thumb by a preceding tendon jerk. In our experiments a maximal H-reflex before a stretch eradicated the late components as well as the early component. If one of the characteristics of long-loop reflexes is that of resistance to vibration and preceding monosynaptic reflex, then this would be evidence against a longloop mechanism for the long-latency reflex of triceps surae.

A final hypothesis for the long-latency reflexes is that they result from Ia input and spinal circuitry. Evidence of this type of hypothesis has been recently produced by Ghez and Shinoda ${ }^{44}$ who described long-latency stretch reflexes in the triceps muscle of decerebrate and spinal cats. This mechanism itself is divisible into two possibilities. Either a single Ia burst of activity produces successive monosynaptic and then polysynaptic reflexes, or several successive Ia bursts may occur each of which produces a monosynaptic reflex. The polysynaptic hypothesis would suggest that the late responses reflect fluctuating levels of excitability in the motor neuron pool which can arise from inputs acting through multiple pathways. Ia polysynaptic pathways indeed have been demonstrated, and can be more obvious during action than at rest. ${ }^{4546}$ Other changes in the neural network of the spinal segment with volition can contribute, for example a change in Renshaw cell behaviour. ${ }^{45} 47$

The possibility that successive Ia bursts can produce multiple EMG responses recently has been suggested by Hagbarth, et $a^{48}$ who have demonstrated multiple Ia bursts by direct recording from human nerves during phasic muscle stretches. Our results are consistent with the hypothesis of Ia mediation and in particular the possibility of successive multiple monosynaptic reflexes. Vibration of the Achilles tendon (or of tibialis anterior) eradicated all components of the long-latency response as well as the short-latency response. As we have noted above, this is consistent with, but does not prove, the notion that the responses are all mediated by a similar input which would be most likely the Ia afferents. The H-reflex experiments done without background force show that a stretch behaved like an Ia volley in producing EMG activity. The $\mathrm{H}$-reflex experiments done with background force, showed that the motor neuron pool was able to respond to at least two inputs at a $30 \mathrm{~ms}$ interval. This was seen with a stretch followed by an H-reflex, and with a small $\mathrm{H}$-reflex followed by a stretch or a small $\mathrm{H}$-reflex followed by a second $\mathrm{H}$-reflex. If the initial stimulus was a large H-reflex, then the second stimulus was ineffective. This would be consistent with the idea that our stretch produced a relatively small Ia volley since it did not inhibit a subsequent $\mathrm{H}$-reflex when there was background force exerted. Other evidence that our stretch was equivalent to a small input volley is that the magnitude of the stretch reflex was small compared to even a moderate H-reflex. Hence, if our stretch produced several serial small Ia volleys, the motor neuron pool should have been able to respond to each volley. The experiments with different durations of stretch showed that the long-latency responses depended on long duration of stretching. The first long-latency component depended on the stretching lasting at least $60 \mathrm{~ms}$, and the second long-latency component depended on the stretching lasting at least $100 \mathrm{~ms}$. Longer duration of stretching allows for the production of additional Ia volleys. We conclude from the H-reflex experiments and the stretches of different duration that long-latency responses in the leg depend on long-duration of stretching and relatively slow acceleration of the stretch (as well as background force). This is the reason that Gottlieb and Agarwal $^{89}$ and Kearney ${ }^{10}$ did not observe these responses.

The quantitative aspects of the long-latency reflexes become understandable with the assumption that we are dealing with multiple Ia bursts. With faster accelerations the first long-latency response begins to plateau and the second long-latency response disappears. This presumably is due to the fact that with larger early components the later components become suppressed; when an early component uses part of the motor neuron pool, this part is unavailable for a later component. The earlier appearance of the second long-latency reflex with respect to the first long-latency reflex, with faster stretches could be due to an earlier third Ia burst.

The long-latency responses seen in triceps surae have obvious similarities to long-latency responses seen in other muscles. The relative latencies of the components are similar. The frequency of appearance of the first and second long-latency reflex in triceps surae is similar to the frequency of appear- 
ance of M2 and M3 in wrist flexors and extensors. ${ }^{457}$ Another similarity is that a long duration of stretching is required for later components in the wrist muscles ${ }^{49}$ as well as in the triceps surae. In addition, reduction of cutaneous and joint afferent input by means of ischaemia has been shown neither to influence the long-latency reflexes in the flexor hallucis longus, nor those in the triceps surae.

There are differences between the long-latency reflexes found in the triceps surae and those in other muscles. The effect of vibration is the most distinct difference. Reduction of cutaneous and joint afferent input, by means of ischaemia, reduces the longlatency responses in the long-thumb flexor, ${ }^{23}$ while the responses from the triceps surae are unaltered. Also, while each long-latency component in the triceps surae does not appear on each individual trial, these components do appear regularly after each stretch of the long-thumb flexor (unpublished observation by Bielawski in our laboratory).

The differences in physiology of long-latency reflexes in different muscles shows that all longlatency reflexes are not the same. The similarities indicate that some of those mechanisms may be shared between all the long-latency reflexes. One of these mechanisms might be the multiple Ia burst phenomenon which sets a background on which other mechanisms can operate.

Alfredo Berardelli was supported by a fellowship from Consiglio-Nazionale Delle Ricerche (CNR) - Nato, Italy. The work was supported by a grant to the Rehabilitation Engineering Center by the NIHR (23-P 5585/1-08) and a grant from the Whittaker Health Sciences Fund of MIT. We are grateful to E Barak who originally built the ankle stretching device as a master's thesis project under the direction of Professor Lawrence Young. D Loo and B Linder helped at various times with technical problems. We thank our colleagues for their helpful comments.

\footnotetext{
References

' Hammond PH. An experimental study of servo action in human muscular contraction. In: Proc. III Int. Conf. Med. Electron. London: Institution of Electrical Engineers, 1960:190-99.

${ }^{2}$ Marsden CB, Merton PA, Morton HB. Servo action in the human thumb. J Physiol (Lond) 1976;257:1-44.

${ }^{3}$ Crago PE, Houk JC, Hasan Z. Regulatory actions of human stretch reflex. J Neurophysiol 1976;39:92535.

${ }^{4}$ Lee RG, Tatton WG. Motor responses to sudden limb displacements in primates with specific C.N.S. lesions and in human patients with motor system disorders. Canad J Neurol Sci 1975;2:285-93.

${ }^{5}$ Lee RG, Tatton WG. Long-loop reflexes in man: clinical
}

applications. In: Desmedt JE, ed. Prog Clin Neurophysiol. Basel: Karger, 1978;6:320-33.

- Evarts EV, Granit R. Relation of reflexes and intended movements. In: Homma S, ed. Understanding Stretch Reflex. Amsterdam: Elsevier, 1976:1-14.

${ }^{7}$ Mortimer JA, Webster DD. Relationships between quantitative measures of rigidity and tremor and the electromyographic responses to load perturbations in unselected normal subjects and Parkinson patients. In: Desmedt JE, ed. Prog Clin Neurophysiol. Basel: Karger, 1978;4:342-60.

${ }^{8}$ Gottlieb GL, Agarwal GC. Response to sudden torques about ankle in man: myotatic reflex. $J$ Neurophysiol 1979;42:91-106.

9 Gottlieb GL, Agarwal GC. Response to sudden torques about the ankle in man: 2-post-myotatic reactions. $J$ Neurophysiol 1980;43:86-101.

${ }^{10}$ Kearney RE. Experimental and simulation studies of ankle reflexes in man. PhD. Thesis at McGill Univ., Montreal, Canada, 1976.

"Melvill Jones G, Watt DGD. Observations on the control of stepping and hopping movements in man. $J$ Physiol (Lond) 1969;219:709-27.

12 Nashner LM. Adapting reflexes controlling the human posture. Exp Brain Res 1976;26:59-72.

${ }^{13}$ Marsden CB, Merton PA, Morton HB, Adam JER, Hallett M. Automatic and voluntary responses to muscle stretch in man. In: Desmedt JE, ed. Prog Clin Neurophysiol. Basel: Karger, 1978;4:167-77.

${ }^{14}$ Hammond PH. The influence of prior instruction to the subject on an apparently involuntary neuromuscular response. J Physiol (Lond) 1956;122:17P-18P.

${ }^{15}$ Kerr B. Task factors that influence selection and preparation for voluntary movements. In: Stelmach GE, ed. Information Processing in Motor Control and Learning. New York: Academic Press, 1978:55-67.

${ }^{16}$ Lance JW McLeod JG. A Physiological Approach to Clinical Neurology, 3rd ed. London: Butterworths, 1981.

${ }^{17}$ Delwaide PJ, Martinelli P, Crenna P. Clinical neurophysiological measurement of spinal reflex activity. In: Feldman RG, Young RR, Koella WP, eds. Spasticity: Disordered Motor Control. Chicago: Yearbook Medical Publishers, 1981:345-71.

${ }^{18}$ Languth HW, Teasdall RD, Magladery JW. Motorneuron excitability following afferent nerve volleys in patients with rostrally adjacent spinal cord damage. Bull Johns Hopk Hosp 1952;91:257-66.

${ }^{19}$ Paillard J. Functional organisation of afferent innervation of muscle studied in man by monosynaptic testing. Am J Phys Med 1959;38:239-47.

${ }^{20}$ Zander O, Diamontopoulos E. Excitability of spinal motor neurons in normal subjects and patients with spasticity, Parkinson rigidity and cerebellar hypotonia. J Neurol Neurosurg Psychiatry 1967;30:325-31.

${ }^{21}$ Chan CWY, Melvill Jones G, Catchlove RFH. The late electromyographic response to limb displacement in man. II. sensory origin. Electroencephalogr Clin Neurophysiol 1979;46:182-8.

${ }^{22}$ Lloyd DP. Integrative pattern of excitation and inhibition in two neuron reflex arcs. $J$ Neurophysiol 1946;9:433-44. 
${ }^{23}$ Marsden CB, Merton PA, Morton HB. The sensory mechanisms of servo action in human muscle. $J$ Physiol (Lond) 1977;265:521-35.

${ }^{24} \mathrm{McGrath}$ GJ, Matthews PBC. Evidence from the use of procaine nerve block that the spindle group II fibers contribute excitation to the tonic stretch reflex of the decerebrate cat. J Physiol (Lond) 1973;235:371-408.

${ }^{25}$ Matthews PBC. Evidence that secondary as well as primary endings of the muscle spindles may be responsible for the stretch reflex of the decerebrate cats. J Physiol (Lond) 1969;204:365-393.

${ }^{26}$ Matthews PBC. A reply to criticism of the hypothesis that the group II afferents contribute excitation to the stretch reflex. Acta Physiol Scand 1970;79:431-3.

${ }^{27}$ Kirkwood PA, Sears TA. Monosynaptic excitation of motoneurons from secondary endings of muscle spindles. Nature 1974;252:243-4.

${ }^{28}$ Kirkwood PA, Sears TA. Monosynaptic excitation of motoneurons from muscle spindle secondary endings of intercostal and triceps surae muscles in the cat. $J$ Physiol (Lond) 1975;245:64-6.

${ }^{29}$ Munson JB, Fleshman JW, Sypert GW. Properties of single-fiber spindle group II EPSP in triceps surae motor neurons. J Neurophysiol 1980;44:713-25.

${ }^{30}$ Stauffer EK, Watt DGD, Taylor A, Reinking RM, Stuart DG. Analysis of muscle receptor connections by spike-triggered averaging 2 . Spindle group II afferents. J Neurophysiol 1976;39:1393-402.

${ }^{31}$ Sypert GW, Fleshman JW, Munson JB. Comparison of monosynaptic actions of medial gastrocnemius group Ia and Group II muscle spindle afferents on triceps surae motoneurons. J Neurophysiol 1980;44:726-38.

${ }^{32}$ Watt DGD, Stauffer EK, Taylor A, Reinking RM, Stuart DG. Analysis of muscle receptors connections of spike-triggered averaging. 1. Spindle primary and tendon organ afferents. $J$ Neurophysiol 1976;39:1375-92.

${ }^{33}$ Burke D, Hagbarth KE, Lofstedt L, Wallin BG,. The responses of human muscle spindle endings to vibration of non-contracting muscles. J Physiol (Lond) 1976;261:673-93.

${ }^{34}$ Burke D, Hagbarth KE, Lofstedt L, Wallin BG. The responses of human muscle spindle endings to vibration during isometric contraction. J Physiol (Lond) 1976;261:695-711.

${ }^{35}$ Evarts EV, Tanji J. Reflex and intended responses in motor cortex pyramidal tract neurons of monkey. $J$ Neurophysiol 1976;39:1069-80.
${ }^{36}$ Marsden CB, Merton PA, Morton HB, Adam JER. The effect of lesions of the central nervous system on long-latency stretch reflexes in the human thumb. In: Desmedt, JE, ed. Prog Clin Neurophysiol. Basel: Karger, 1978;4:334-41.

${ }^{37}$ Phillips CG. Motor apparatus of the baboon's hand. Proc $R$ Soc B 1969;173:141-74.

${ }^{38}$ Phillips CG, Powell TPS, Wiesendanger M. Projection from low-threshold muscle afferents of hand and forearm to area 3a of baboon's cortex. J Physiol (Lond) $1971 ; 217: 419-46$.

${ }^{39}$ Pagni CA, Ettore G, Infuso L, Marossero F. EMG responses to capsular stimulation in the human. Experientia 1964;20:691-2.

${ }^{40}$ Starr A, Burke B, McKeon B, Skuse N. Stretch evoked somatosensory potentials in man. Brain $1981 ; 104: 149-66$.

${ }^{41}$ Hendrie A, Lee RG. Selective effects of vibration on human spinal and long-loop reflexes. Brain Res 1978;157:369-75.

${ }^{42}$ Cooke JD, Eastman MJ. Long loop reflexes in the tranquilised monkey. Exp Brain Res 1977;27:491-500.

${ }^{43}$ Marsden CB, Merton PA, Morton HB. Stretch reflex and servo action in a variety of human muscles. $J$ Physiol (Lond) 1976;259:531-60.

${ }^{44}$ Ghez C, Shinoda Y. Spinal mechanisms of the functional stretch reflex. Exp Brain Res 1978;32:55-68.

${ }^{45}$ Hultborn H, Pierrot-Deseilligny E. Changes in recurrent inhibition during voluntary soleus contractions in man studied by an H-reflex technique. J Physiol (Lond) 1979;297:229-51.

${ }^{46}$ Schomburg ED, Behrends HB. The possibility of phase-dependent monosynaptic and polysynaptic Ia excitation to homonymous motoneurons during fictive locomotion. Brain Res 1978;143:533-7.

${ }^{47}$ Hultborn H, Wigstrom H, Wangberg B. Prolonged excitation in motoneurons triggered by activity in Ia afferents. Acta Physiol Scand (Suppl) 1976;440:62.

${ }^{48}$ Hagbarth KE, Hagglund J, Wallin V, Young RR. Grouped spindle and electromyographic responses to abrupt wrist movements in man. J Physiol (Lond) 1981;312:81-96.

${ }^{49}$ Lee RG, Tatton WG. Long-latency versus long-loop reflexes: dependence on the temporal characteristics of the imposed displacement. Soc Neurosci Abstr 1979;5:367. 